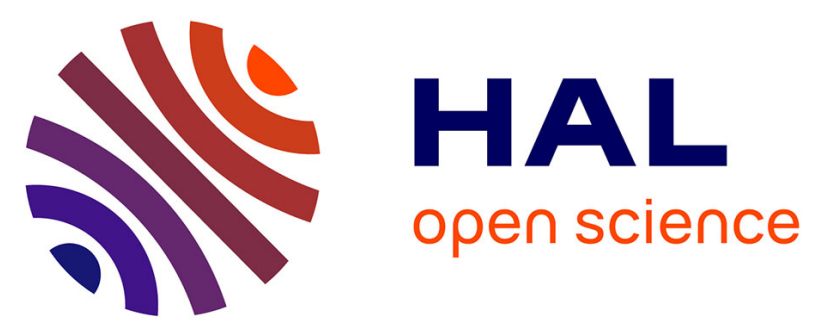

\title{
Formation of inverse cones in crystalline silicon by selective etching of amorphous regions resulting from epitaxial breakdown
}

\author{
H Mohsin, W Chen, D Daineka, P Roca I Cabarrocas, E Johnson
}

\section{To cite this version:}

H Mohsin, W Chen, D Daineka, P Roca I Cabarrocas, E Johnson. Formation of inverse cones in crystalline silicon by selective etching of amorphous regions resulting from epitaxial breakdown. Journal of Physics D: Applied Physics, 2021, 54 (49), pp.495103. 10.1088/1361-6463/ac22d8 . hal-03383213

\section{HAL Id: hal-03383213 \\ https://hal.science/hal-03383213}

Submitted on 18 Oct 2021

HAL is a multi-disciplinary open access archive for the deposit and dissemination of scientific research documents, whether they are published or not. The documents may come from teaching and research institutions in France or abroad, or from public or private research centers.
L'archive ouverte pluridisciplinaire HAL, est destinée au dépôt et à la diffusion de documents scientifiques de niveau recherche, publiés ou non, émanant des établissements d'enseignement et de recherche français ou étrangers, des laboratoires publics ou privés. 


\title{
Formation of inverse cones in crystalline silicon by selective etching of amorphous regions resulting from epitaxial breakdown
}

\author{
H. Mohsin ${ }^{1,+}$, W. Chen ${ }^{1,+\dagger}$, D. Daineka ${ }^{1}$, P. Roca i Cabarrocas ${ }^{1}$ and E. V. Johnson ${ }^{1 *}$ \\ ${ }^{1}$ Laboratoire de Physique des Interfaces et des Couches Minces, CNRS, Ecole Polytechnique, \\ Institut Polytechnique de Paris, 91128 Palaiseau, France \\ ${ }^{\dagger}$ Current address: Laboratoire Surface du Verre et Interfaces, UMR 125, CNRS/Saint-Gobain, \\ 93303 Aubervilliers, France \\ ${ }^{+\dagger}$ Current address: School of Physical Science and Technology, Ningbo University, 315211 Ningbo, \\ China \\ * Corresponding author: erik.johnson@polytechnique.edu
}

\begin{abstract}
We report on a process to form micron-scale inverse cones in crystalline silicon without any masking steps using a selective, low temperature $\left(<175^{\circ} \mathrm{C}\right)$ plasma process. The selectivity of the process originates from the use of a $\mathrm{H}_{2}$ plasma that preferentially etches away amorphous cones, formed as a result of epitaxial breakdown, leaving the surrounding crystalline material behind. Efficient etching is realized by pre-coating the reactor walls with hydrogenated amorphous silicon oxide $\left(\mathrm{a}-\mathrm{SiO}_{\mathrm{x}}: \mathrm{H}\right)$ to prevent any chemical transport of silicon towards the substrate. The etch depth of the amorphous cones is linked directly to the time of exposure to plasma. When densely packed, such structures exhibit useful optical properties, such as specular reflectance as low as $2 \%$ (with the sample appearing visibly black in the high density and fully etched regions) and iridescence (in regions of partial etching).
\end{abstract}

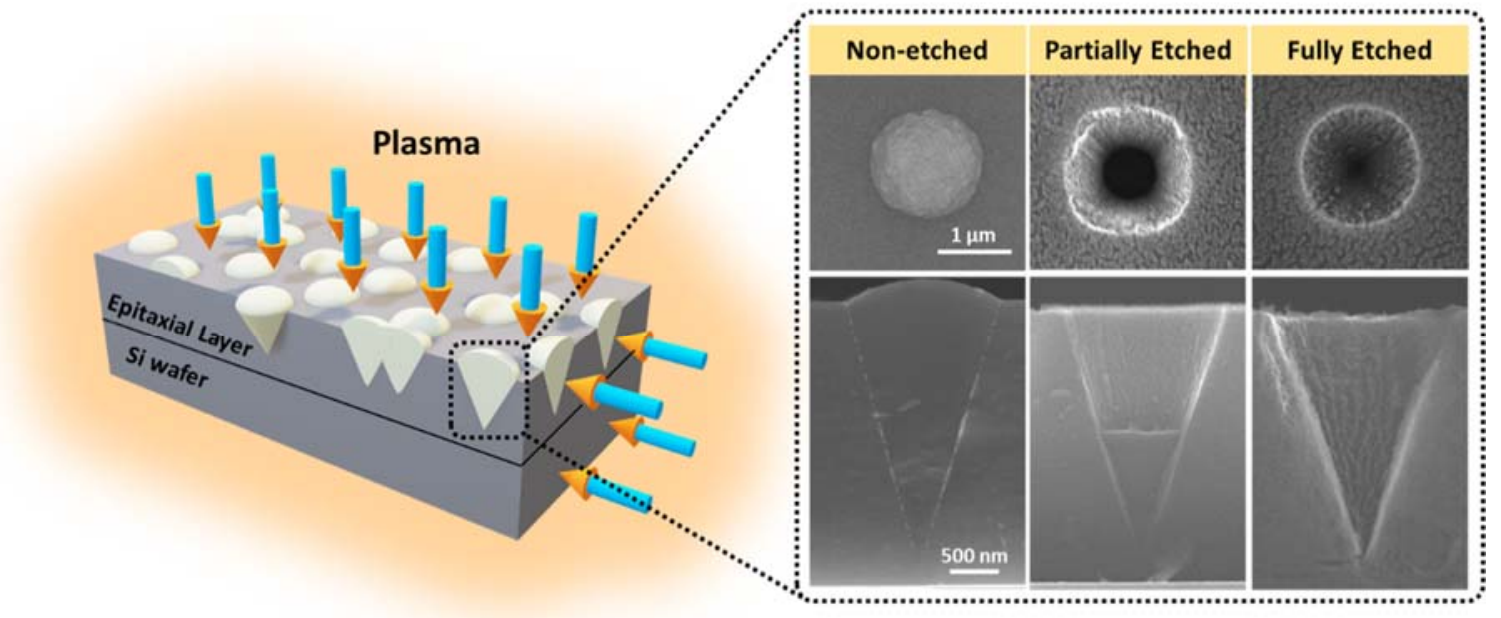

Keywords: Selective etching, Epitaxial breakdown, Plasma processing, Light trapping, Iridescence

\section{Introduction}

Low temperature $\left(<500^{\circ} \mathrm{C}\right)$ epitaxial growth of crystalline silicon (c-Si) is a promising technology for applications such as photovoltaics and flexible electronics. It can be achieved by multiple vacuum deposition methods, including molecular beam epitaxy (MBE) [1], hot-wire chemical vapour deposition (HWCVD) [2] and plasma-enhanced CVD (PECVD) [3-5]. In particular, the use of PECVD allows one to 
perform epitaxy at temperatures as low as $175^{\circ} \mathrm{C}$, and produce films with a variety of doping properties and sharp doping profiles [6-9].

A common property amongst these low temperature techniques is the manner in which growth proceeds when the epitaxy fails, or "breaks down". Epitaxial breakdown typically begins at a point (or rather, many discrete points), and the layer growing on top of the breakdown point (a) is fully amorphous, without any crystalline component, and (b) grows faster than in the surrounding area, resulting in a buried, inverse cone structure (as shown in Figure 1). The reasons behind the initial failure have been attributed to stress and to hydrogen accumulation $[2,3,10,11]$, but such structures are common to all low temperature epitaxial growth techniques.
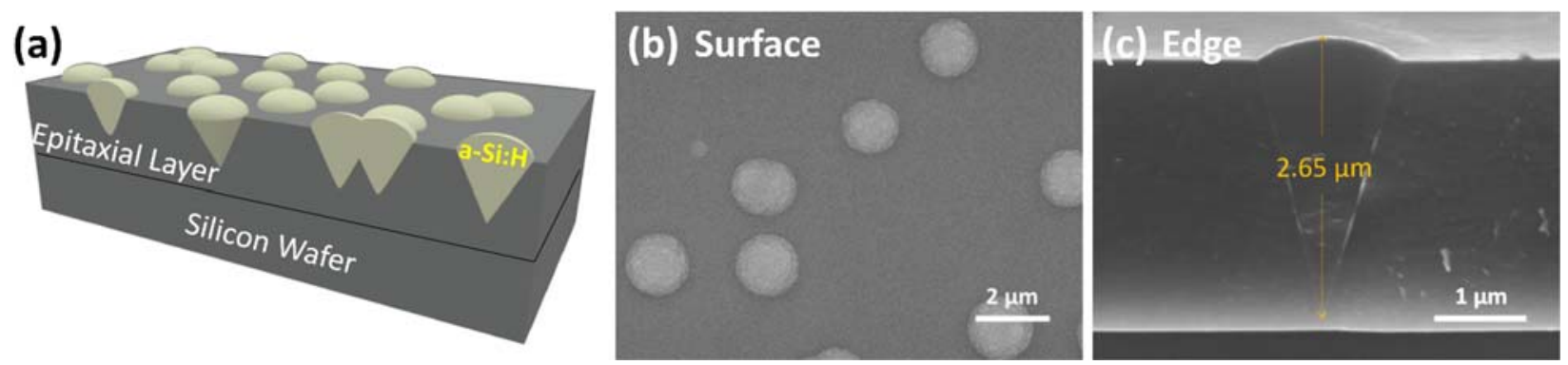

Figure 1: Illustration of epitaxial breakdown indicating amorphous cones embedded in c-Si epitaxial layer; (a) 3D schematic and (b, c) SEM images showing the top and cross-sectional views.

The inverted cones have been previously confirmed to be fully amorphous through multiple complementary techniques [11]. If these amorphous cones were to be removed, one would be left with a series of conical holes or "inverted cones". Similar structures ("inverted pyramids", produced by patterning and etching a surface) are widely recognized as a very efficient light-trapping structure for crystalline silicon solar cells [12-16], although slightly less efficient structures ("pyramids") are used in practice due to their ease of fabrication $[17,18]$.

In this work, we aim to exploit the structures resulting from epitaxial breakdown by demonstrating a strategy to selectively etch away the amorphous cones while leaving the crystalline areas relatively untouched. We do so using a low temperature $\left(<175^{\circ} \mathrm{C}\right)$, selective $\mathrm{H}_{2}$ plasma process that etches amorphous silicon material faster that its crystalline counterpart.

\section{Experimental Methods}

Sample Processing: The samples were prepared as described in Ref [11] under conditions resulting in epitaxial breakdown. After cleaving, the samples were irregularly shaped, but approximately $25 \mathrm{~mm} x$ $10 \mathrm{~mm}$ in size. Native oxide formed on these samples as they were stored in ambient conditions for several months. This is an interesting aspect from an industrial point of view as it indicates that the developed process does not require particular attention with respect to the storage of the epitaxial layers (such as in a glove box or $\mathrm{N}_{2}$ ambient). The etching processes were done in a custom-made RFPECVD reactor [19] with walls coated in either hydrogenated amorphous silicon (a-Si:H) or hydrogenated amorphous silicon oxide (a-SiOx:H). Before the selective etching process, samples were exposed to a brief $\mathrm{SiF}_{4}$ plasma to remove the native oxide. The main selective etching process was a pure $\mathrm{H}_{2}$ plasma, which is known to be selective between crystalline silicon and a-Si:H, etching the latter at a rate up to 10 times faster than the former [20]. The PECVD reactor is designed so that samples can be rotated in and out of the plasma zone after stabilization, allowing one to perform a process on the chamber walls to 
which the sample is not exposed, without breaking vacuum. Samples can also be placed on the radio frequency (RF) electrode, subjecting them to a higher ion bombardment energy level. The range of experimental conditions used is presented in Table 1.

Table 1: Parameters involved in three-step selective etching process.

\begin{tabular}{|c|c|c|c|c|c|c|c|}
\hline \multicolumn{3}{|c|}{ Step } & \multirow{2}{*}{$\begin{array}{l}\begin{array}{l}\text { Temp. } \\
\left({ }^{\circ} \mathrm{C}\right)\end{array} \\
175\end{array}$} & \multirow{2}{*}{$\begin{array}{l}\begin{array}{l}\text { Gas Flows } \\
\text { (sccm) }\end{array} \\
\mathrm{H}_{2} / \mathrm{SiH}_{4}=100 / 30\end{array}$} & \multirow{2}{*}{$\begin{array}{l}\text { Power } \\
\left(\mathrm{mW} / \mathrm{cm}^{2}\right)\end{array}$} & \multirow{2}{*}{$\begin{array}{l}\begin{array}{l}\text { Pressure } \\
\text { (Torr) }\end{array} \\
0.15\end{array}$} & \multirow{2}{*}{$\begin{array}{l}\text { Time } \\
\text { (min) }\end{array}$} \\
\hline & Reactor wall & a-Si:H & & & & & \\
\hline & pre-treatment & $\mathrm{a}-\mathrm{SiO}_{\mathrm{x}}: \mathrm{H}$ & 175 & $\mathrm{H}_{2} / \mathrm{SiH}_{4} / \mathrm{CO}_{2}=400 / 1.5 / 10$ & 96 & 1 & 15,25 \\
\hline 2 & \multicolumn{2}{|l|}{$\mathrm{SiF}_{4}$ plasma } & $120 / 175$ & $\mathrm{SiF}_{4}=20$ & 60 & 0.2 & 3 \\
\hline 3 & \multicolumn{2}{|l|}{$\mathrm{H}_{2}$ plasma } & $120 / 175$ & $\mathrm{H}_{2}=500$ & $180 / 300$ & $0.2 / 0.5 / 1$ & $10,18,45$ \\
\hline
\end{tabular}

Characterization Techniques: Scanning electron microscopy (SEM) observations of the samples were carried out on a HITACHI S-4800 microscope with a field emission source at $10 \mathrm{kV}$ or $20 \mathrm{kV}$ and $5 \mu \mathrm{A}$ (using the upper detector). For cross-sectional images, samples were either cleaved after processing (to see the cross section for a central part) or observed on an edge. An Agilent Technologies Cary 5000 series spectrophotometer was used to measure the specular reflectance at $10^{\circ}$ with respect to the sample surface normal.

\section{Results and Discussion}

\subsection{Effect of reactor wall coating}

A first set of experiments were done to measure the role of the reactor wall coating on the etching process. Two different reactor wall coatings were used: a-Si:H and a-SiO $\mathrm{x}: \mathrm{H}$ (deposited from a mixture of $\mathrm{SiH}_{4}$ and $\mathrm{CO}_{2}$, Table 1). Such processes would have coated the walls with $30-75 \mathrm{~nm}$ of a-Si:H or a-SiO $: \mathrm{H}$. After the brief $\mathrm{SiF}_{4}$ plasma to remove native oxide from the epitaxial layer, the $\mathrm{H}_{2}$ plasma process was performed at 1 Torr, for 45 minutes, and at a temperature of $175^{\circ} \mathrm{C}$.

Figure 2(a) and (b) show SEM images of the sample surface when the reactor walls were coated with a$\mathrm{Si}: \mathrm{H}$. It can be seen that the etching process does not have a significant impact on the dome-like structures that indicate the presence of the epitaxial breakdown points. A roughening of the surface of the dome is observed in the zoomed-in image in Figure 2(b) but etching was negligible. Conversely, Figure 2(c) and (d) show the results when the same etching process was performed on a sample where the reactor walls were coated with a-SiO $: \mathrm{H}$. Viewed from above (Figure 2(c)), the amorphous dome has been etched away, and hollow inverse cones begin to appear. The cross-sectional view shown in Figure 2 (d) confirms this observation. In this case the process was stopped before the bottom of the cone was reached, so one can still see the amorphous section at its bottom. 

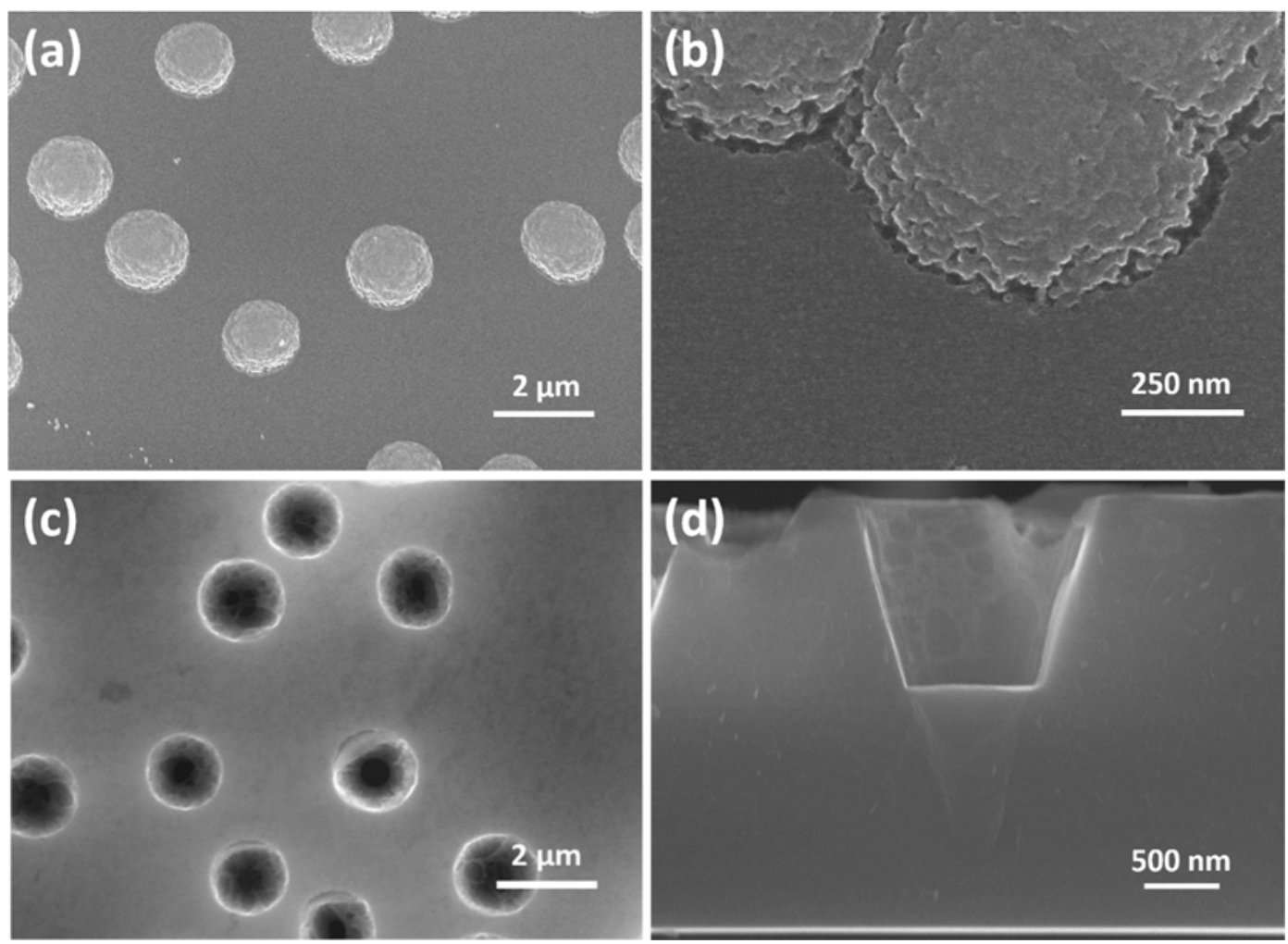

Figure 2: SEM images of surfaces after etching when reactor walls are coated with (a, b) a-Si:H and (c, d) a-SiOx:H. No etching of the amorphous part is observed in $(a, b)$ while cones are partially etched in (c, d) which show the top and cross-sectional view of the inverse cones, respectively.

The difference between these two results underlines the selectivity of $\mathrm{H}_{2}$ plasma to the surface being etched. The a-Si:H on the walls of the reactor is so readily etched by the $\mathrm{H}_{2}$ plasma that when a significant amount of the wall is covered in this material, it can contribute enough growth precursors to incite growth on other surfaces (such as the substrate). This process has been called chemical transport [21], and typically results in nanocrystalline silicon growth [22] (a material which also then resists $\mathrm{H}_{2}$ plasma etching better than a-Si:H [23]). This is presumably the process occurring in Figure 2(a) and (b); chemical transport from the walls to the substrate is preventing the etching of the amorphous cones. However, both c-Si and a-SiO ${ }_{x}: \mathrm{H}$ are resistant to $\mathrm{H}_{2}$ plasma, and therefore do not contribute to chemical transport. In this case (Figure 2(c) and (d)), the amorphous cones can thus be effectively etched away.

Cross-sectional images of the cones before and after etching (such as in Figure 3 ) demonstrate the selectivity of the $\mathrm{H}_{2}$ plasma between a-Si:H and c-Si, that is, the large difference in etching rate. The half-angle of the cone increases from $16^{\circ}$ before etching, to $19.3^{\circ}$ after etching. Assuming an isotropic etching process, and that the etching process was stopped immediately once the bottom of the cone was reached, one can derive a formula relating the cone half-angles before $\left(\theta_{i}\right)$ and after $\left(\theta_{f}\right)$ etching to the relative etching rate, $\eta$, given as $\eta=\tan \theta_{i} / \cos \left(\theta_{f}-\theta_{i}\right)$. Using the values of angle from Figure 3 , one obtains an etching rate ratio of $\sim 17$ for the plasma conditions used herein. This value can be compared to the value of $\sim 10$ claimed in Ref [20], indicating that some anisotropy is present in the process (which is also suggested by the slight outward curve of the sidewalls in Figure $3 \mathrm{~b}$. 


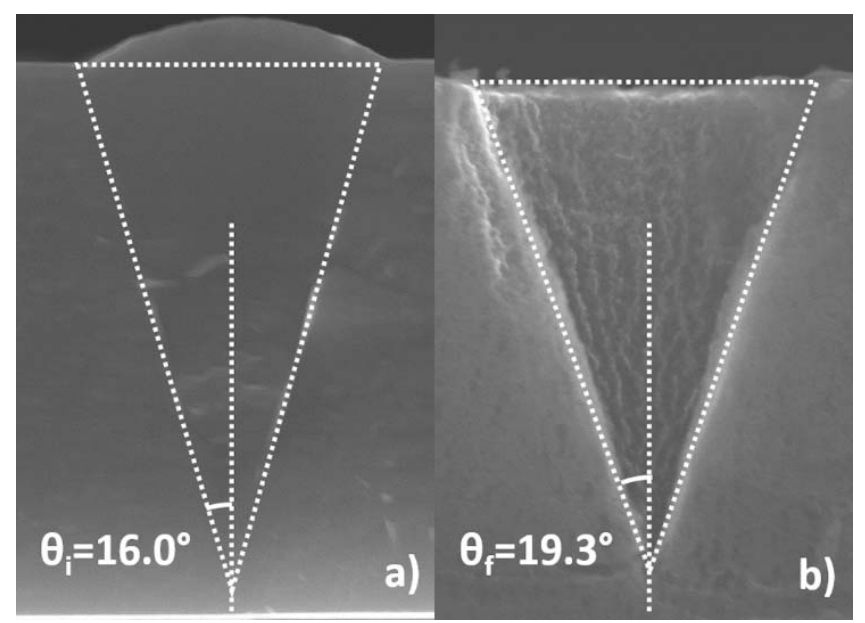

Figure 3: Cross-sectional SEM images of (a) amorphous cone before etching, and (b) inverted cone after etching.

Furthermore, the stability of silicon oxide in an $\mathrm{H}_{2}$ plasma is underlined by the images of the etched cones in Figure 4 . For this sample (with a medium density of cones, 31 cones $/ 100 \mu \mathrm{m}^{2}$ ), a lacework-like covering over the holes can be seen which is more evident from the zoomed-in image in Figure 4(b). This appears to be the residual oxide from the amorphous cones that was incompletely etched by the initial $\mathrm{SiF}_{4}$ plasma. The fact that this thin lacework remains after the $\mathrm{H}_{2}$ plasma exposure underlines how resistant silicon oxide is to $\mathrm{H}_{2}$ plasma, and why it is therefore so effective when used as a wall coating to prevent chemical transport (as discussed for Figure 2). 

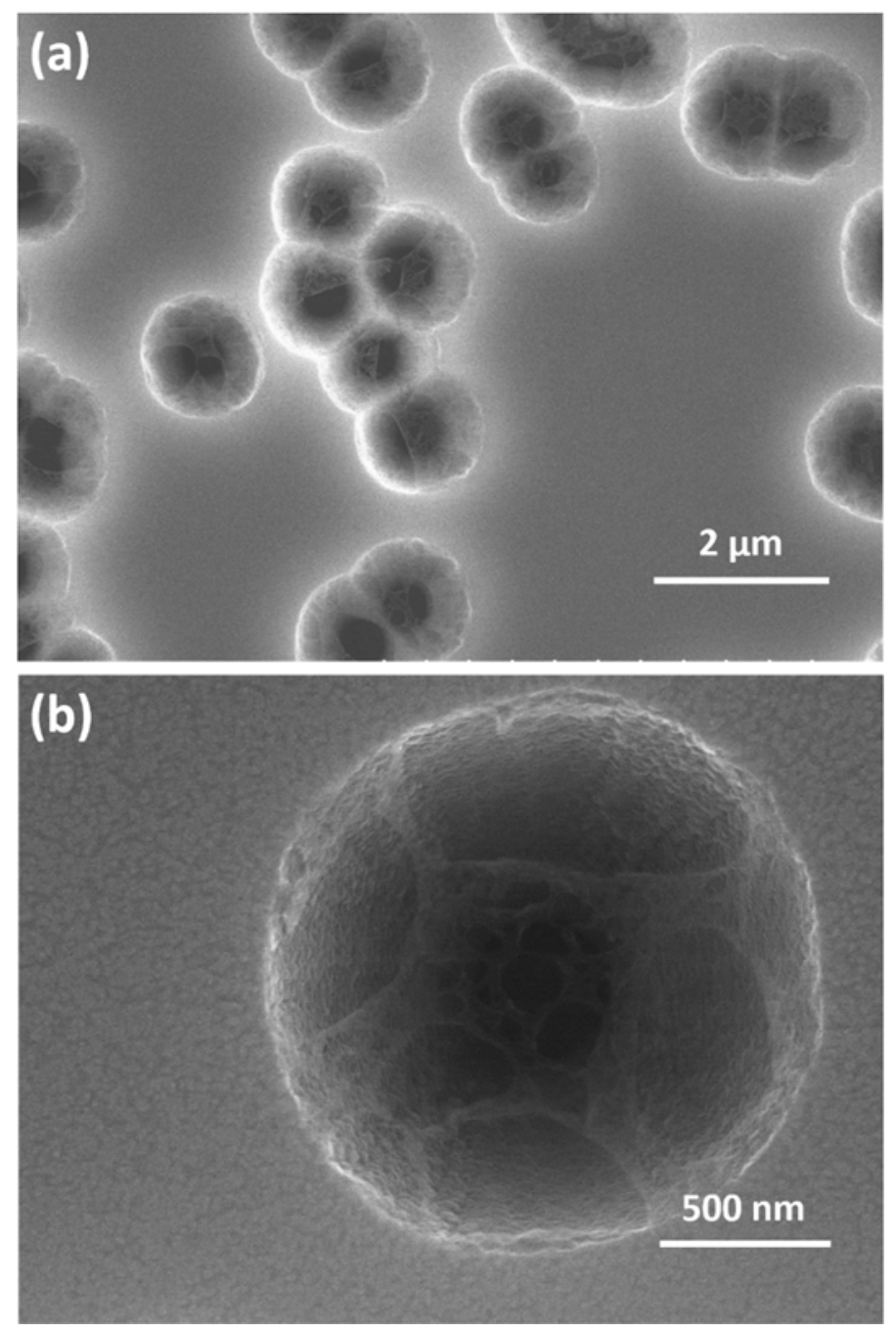

Figure 4: (a) and (b) SEM Images showing lace-like films remaining over the top of etched holes.

\subsection{Influence of plasma parameters}

To explore the effect of process plasma parameters on the effect being studied, three different pressures and two temperatures were employed. Figure 5 shows the variation in the extent of etching of amorphous inverted cones for total pressures of $0.2,0.5$ and 1 Torr. The data points in Figure 5 represent mean depth of etching in central region of the samples and hence the corresponding error bars are calculated. Note that the height of dome-like structures $(\sim 200 \mathrm{~nm})$ on top of the amorphous cones has not been considered.

Pressure: The depth of etching of the amorphous cones increases with the duration of exposure to $\mathrm{H}_{2}$ plasma. Error bars indicate the variation in etch depth on each sample near the center of the sample. Etch rates between 0.4 and $1.1 \mathrm{~nm} / \mathrm{s}$ are observed. Similar etch depths are observed for the samples that underwent plasma treatments at 0.2 and 0.5 Torr. An etch depth of $1 \mu \mathrm{m}$ is observed at 1 Torr after $45 \mathrm{~min}$, which is $300 \mathrm{~nm}$ less than the average etch depth at 0.5 Torr, but with greater uniformity, as indicated by the error bars. Overall, in the range explored, the process pressure does not dramatically impact the etching rate at constant temperature and for samples placed in the sample holder. However, the process pressure can have other, more detailed effects. For example, reducing the pressure tends to reduce the amount of lace-like films of residual oxide from the top of etched cones. 


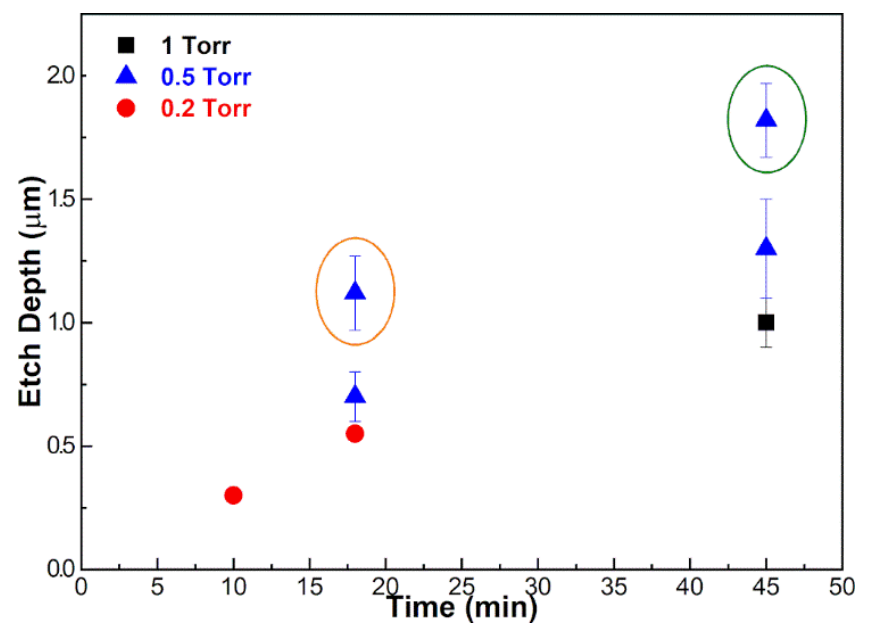

Figure 5: Variation in the etch depth (in the middle region) as a function of time for the different pressures used. All the data points correspond to a process temperature of $175^{\circ} \mathrm{C}$ except for the point highlighted with orange circle which represents $120^{\circ} \mathrm{C}$. Etch depth of the sample placed directly on the bottom RF electrode is highlighted by the green circle.

Temperature: In contrast, process temperature influences the rate of selective etching more strongly. A reduction in temperature from $175^{\circ} \mathrm{C}$ to $120^{\circ} \mathrm{C}$ approximately doubles the etch rate, as exhibited by the sample circled in orange in Figure 5 . This may be caused by a reduction in diffusion of hydrogen within the sample, accompanied by an increase in the flux of atomic hydrogen from the plasma [24].

Ion Bombardment Energy: The data point marked with a green circle in Figure 5 represents the sample that was placed directly on the bottom RF electrode instead of the sample holder, and so was subject to a greater ion bombardment energy during the process. Images of this sample, as well as the one placed on the grounded sample holder during the same process, are presented in Figure 6 . The images have been aligned vertically so that the initial surface of the wafer (before epitaxy) is at the same vertical position. As the samples were the same initial thickness, one can note a loss of etching selectivity in this case, as $\sim 500 \mathrm{~nm}$ of the crystalline part of the epitaxial layer is also etched due to an intense bombardment by incoming hydrogen ions (most likely $\mathrm{H}_{3}{ }^{+}$). An increased amorphous layer etching rate of $0.67 \mathrm{~nm} / \mathrm{s}$ is achieved for this sample (compared to the sample co-processed but placed in the sample holder), at the cost of a loss in selectivity. 


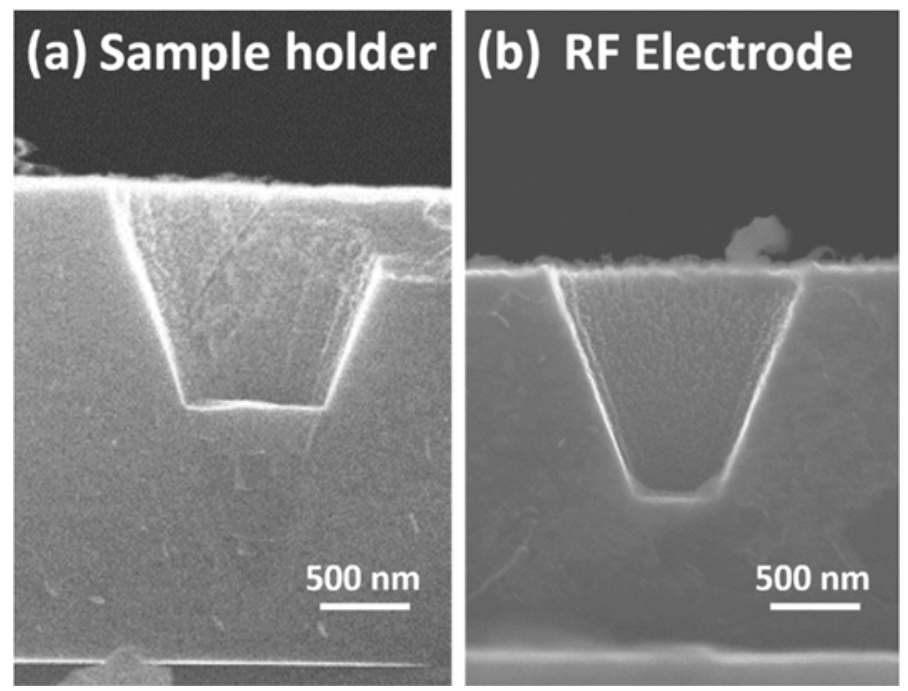

Figure 6: Cross-sectional SEM images of co-processed samples placed (a) on the substrate holder, and (b) on the RF electrode.

\subsection{Sources of non-uniformity}

Two sources contribute to an aerial non-uniformity in the outcome of the process: initial density of cones, and proximity of cones to the edge of the substrate. The initial density of cones is determined by the epitaxial breakdown process, and varies from 4 cones $/ 100 \mu \mathrm{m}^{2}$ (fig. $7 \mathrm{~b}$ ) to 78 cones $/ 100 \mu \mathrm{m}^{2}$ (fig.7d) for the samples used in this study. Because epitaxial breakdown was an undesired result from another study [11], no particular effort was made to control the density of breakdown points (and the resulting cones). In addition to this non-uniformity from the initial samples, of more importance is an observed dependence of the etching rate on proximity to the edge of the sample, as this source of inhomogeneity may be process parameter dependent. Examples of both of these sources of inhomogeneity are presented in Figure 7, showing the top-view images in the central region and edge of the sample. Two types of areas are shown, having either a low (4-6 cones / $\left.100 \mu \mathrm{m}^{2}\right)$ or high (64-78 cones $/ 100 \mathrm{\mu m}^{2}$ ) density of etched amorphous cones 

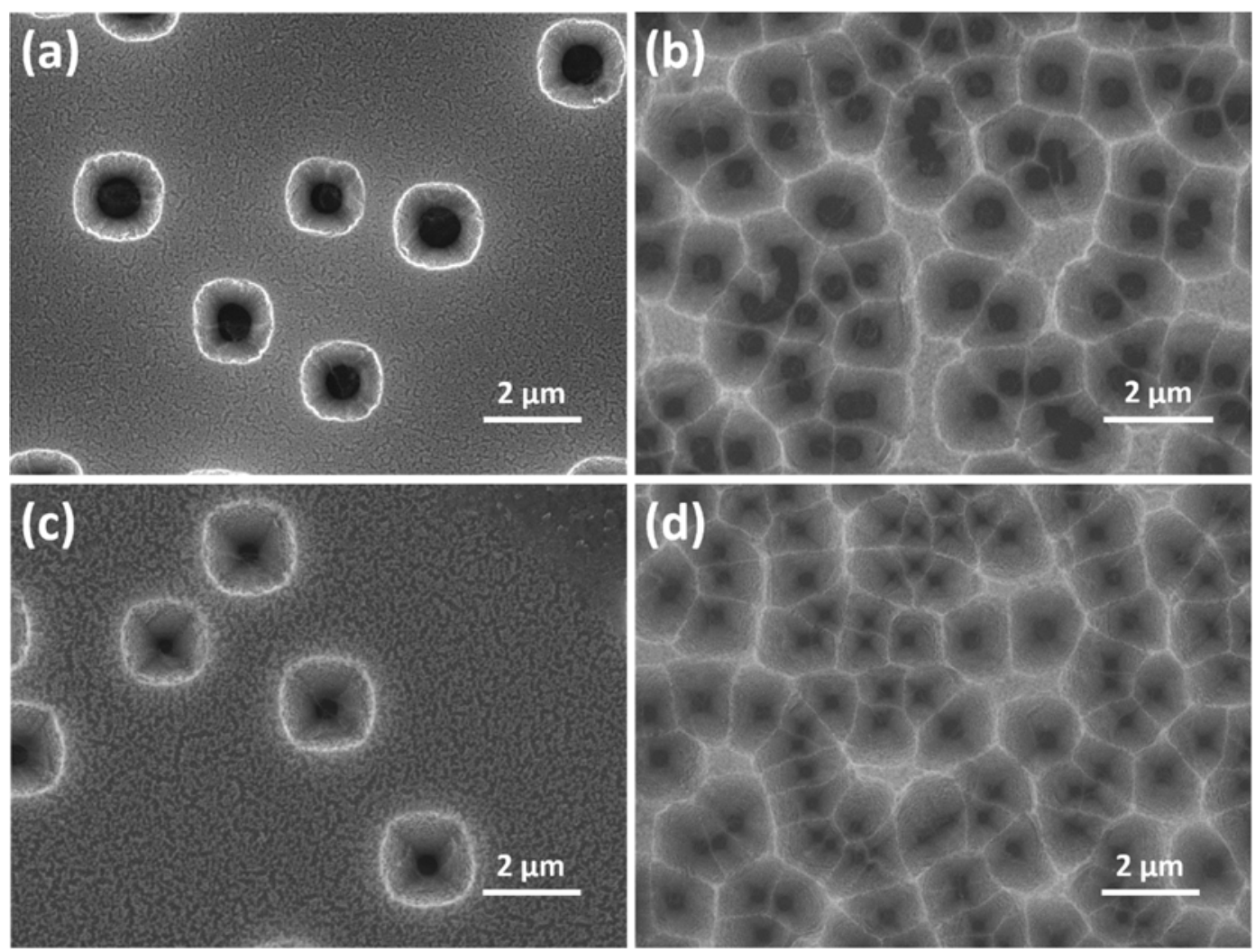

Figure 7: SEM images showing inhomogeneities in process outcome. (a) and (c) are for areas with low initial cone density and at the sample centre $\left(\mathrm{a}, 6\right.$ cones $\left./ 100 \mu \mathrm{m}^{2}\right)$ or at the edge $\left(\mathrm{c}, 4\right.$ cones $\left./ 100 \mu \mathrm{m}^{2}\right)$. Subfigures (b) and (d) are for areas with high initial cone density, at the sample centre $\left(b, 64\right.$ cones $\left./ 100 \mu \mathrm{m}^{2}\right)$ or at the edge $(d, 78$ cones/ $\left.100 \mu \mathrm{m}^{2}\right)$.

The etch depth is higher for the cones along the edge $(\sim 2.2 \mu \mathrm{m})$ than in the middle region $(\sim 1.3 \mu \mathrm{m})$ (Figure $7 a$ vs $7 c$, and Figure $7 b$ vs $7 d$ ). This can be seen from the size of the black spot (which corresponds to the bottom of the etched part of the cone), but has also been quantified using crosssectional SEM images (not shown here but provided in the graphical abstract of the manuscript as an example). Furthermore, as the proximity to the edge changes, the profile of the holes as observed from above changes too, and facets of inverted pyramids appear, most clearly seen in Figure 7 (b). The density of cones does not seem to affect the etch rate or faceting of the holes as much as proximity to the edge, suggesting some micro-loading effects [25]. In an extreme case, when cones are exposed to the $\mathrm{H}_{2}$ plasma from the side (such as when a sample is cleaved and the edge of a cone is exposed from the side), even a solitary cone will be etched away completely. Nevertheless, the process still remains very selective, etching the amorphous material much more quickly than the surrounding crystalline volumes.

\subsection{Optical properties of samples after etching}

Reflectance measurements: The areas containing etched, inverted cones display optical properties that are immediately obvious to the naked eye. In areas where a high density of inverted cones is present and etching has been done almost to completion, the optical reflectivity of the surface is notably reduced, and the sample appears "black". However, this feature only appears when the surface is almost completely composed of etched cones, and so some discussion on areal cone density is warranted. 
Taking the half-angle of the inverted etched cone tip as $\theta_{f}$ (measured as $19.3^{\circ}$ in Figure 3 ), then the surface area filled by the cone "base" will depend on the film thickness, $t$, and can be estimated as $A_{\text {surf }}=\pi t^{2} \tan ^{2} \theta_{f}$. This expression can be inverted to estimate the density of cones necessary (for a given t) to achieve complete surface coverage, $N_{\text {full }}=1 / \pi t^{2} \tan ^{2} \theta_{f}$. To take into account the fact that the cone bases will be round (as opposed to hexagons, which would be able to fill the surface without overlap), we must add an additional factor of $2 \pi /(3 \sqrt{3})$, giving the expression

$$
N_{\text {full }}=2 / 3 \sqrt{3} t^{2} \tan ^{2} \theta_{f}
$$

Using the value of as $\theta_{f}=19.3^{\circ}$ from Figure 3 , this becomes $N_{f u l l, 19.2^{\circ}} \approx 22 /\left(7 t^{2}\right)$. For the film thicknesses used in this work $(2.2 \mu \mathrm{m})$, we obtain the value of $N_{\text {full }}=65 \mathrm{cones} / 100 \mu \mathrm{m}^{2}$. This value (and the equation used to calculate it) assumes a perfect, hexagonally close-packed arrangement for the cones, and does not account for the fact that the cones will be randomly placed. However, it does give a useful order-of-magnitude value for comparison. For example, in fig. $7 \mathrm{~b}$, almost this exact density of cones is present $\left(64\right.$ cones $\left./ 100 \mu \mathrm{m}^{2}\right)$. However, due to the random placement of the cones, many flat areas can still be observed. In fig $7 d$, the random placement of cones is compensated by a greater density ( 78 cones $/ 100 \mu \mathrm{m}^{2}$ ), and the remaining flat areas are fewer.

The optical reflectivity of the high density $\left(>65\right.$ cones $/ \mu \mathrm{m}^{2}$ ) etched regions has been quantified though specular reflectance measurements, presented in comparison to a bare crystalline Si wafer (Figure 8). The reflectance is as low as $7 \%$ and $2 \%$ in the visible range for samples exposed to $\mathrm{H}_{2}$ plasma for $45 \mathrm{~min}$ at 1 Torr and 0.5 Torr, respectively, which corresponds to a reduction in reflectance between $25-45 \%$ as compared to a bare c-Si wafer. Since the etch depth is higher at 0.5 Torr (as shown in Figure 4), the cone is more completely etched, and a higher light trapping is expected as the horizontal surface from which reflection could occur is minimized.

One possible domain where such a property could find an application is in improving the light trapping properties of the surfaces of photovoltaic devices. However, for this application, the use of a $2.2 \mu \mathrm{m}$ epitaxial layer with $>64$ cones/ $100 \mu \mathrm{m} 2$ may not be optimal. Current, state of the art crystalline silicon devices use 150-180 $\mu \mathrm{m}$ thick wafers, with texturing using pyramids with heights between 5-10 $\mu \mathrm{m}$. In the future, thinner wafer technologies would aim for thinner textures [26], requiring a thinner epitaxial layer when using the technique described in this paper. To enable the use of a thinner epitaxial layer, one would need to increase the density of initial breakdown points (as explained above). Rather than rely on spontaneous epitaxial breakdown as done in this study, intentionally disrupting the initial phase of epitaxy would be a better strategy. This could be done with an external surface treatment, or by using an initial pulsed plasma process allowing large particles to escape and deposit on the surface [27] to interrupt epitaxy. For example, by increasing the density of epitaxial "interruption" points to 800 per $100 \mu^{2}$ (as displayed in the results of [27]), the required thickness of epitaxy becomes only $620 \mathrm{~nm}$, and the technique becomes compatible with ultra-thin crystalline silicon cells [26]. Furthermore, by intentionally interrupting epitaxy, one would not need to rely on using epitaxial conditions designed to cause breakdown [11], and could aim to produce the highest possible quality of epitaxial layer. 


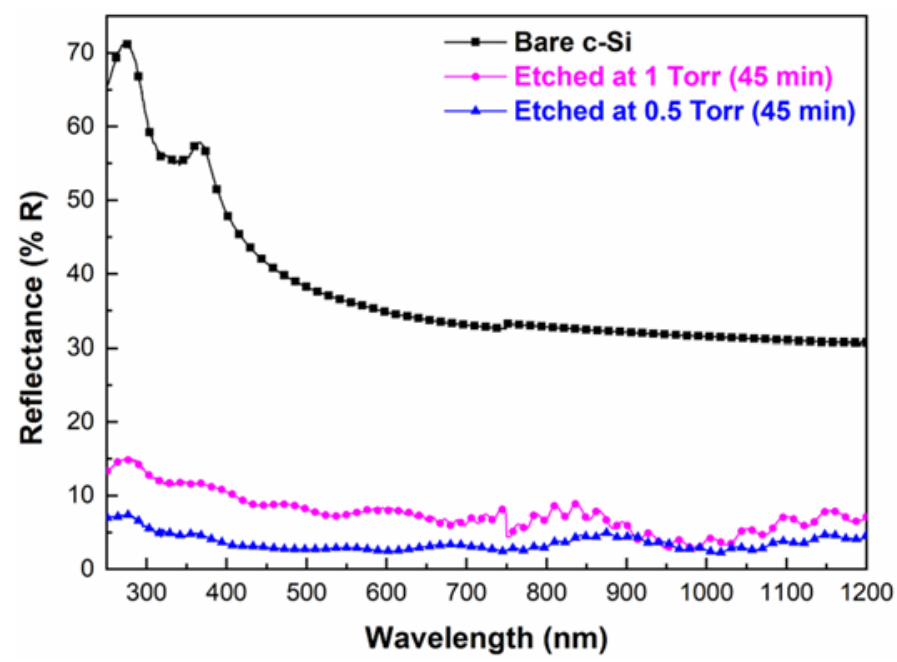

Figure 8: Specular reflectance response of bare c-Si wafer and etched inverted cone epitaxial layers. Offset observed at $750 \mathrm{~nm}$ is due to the grating calibration of the equipment.

Iridescence effect: Samples having undergone a partial etching of the amorphous, inverted cones show a different optical effect, namely iridescence, changing color upon changing the angle of view or illumination. This can be seen in Figure 9(a), and is the result of interference effects due to reflections from two flat but parallel surfaces i.e. the crystalline surface of the epitaxial layer and flat-bottomed region of the partially etched cones (schematically shown Figure 9(b)). This is an unusual phenomenon, as surfaces displaying iridescence typically do so due to thin-film interference effects or diffractive elements. In the samples presented herein, the uniform etching of the inverted amorphous cones (and their flat surfaces before complete etching) provides the path length difference necessary for interference, and therefore iridescence.

Samples displaying such properties are obviously not optimized for light trapping applications, but this unusual effect could be used as an in-situ measure of process completion. Such structures could also be useful in sensing, as the iridescence is caused by a path difference through air, and if the volume of the holes were filled with another substance, the optical response would change. For either of these applications, the equation for optimal surface filling for light-trapping would no longer be appropriate, and a cone density giving a surface filling of $\sim 50 \%$ would be optimal. In this case, for the sparser cones, the equation for round surface structures could be used, giving

$$
N_{\text {opt,iridescence }}=1 / 2 \pi t^{2} \tan ^{2} \theta_{f}
$$


(a)
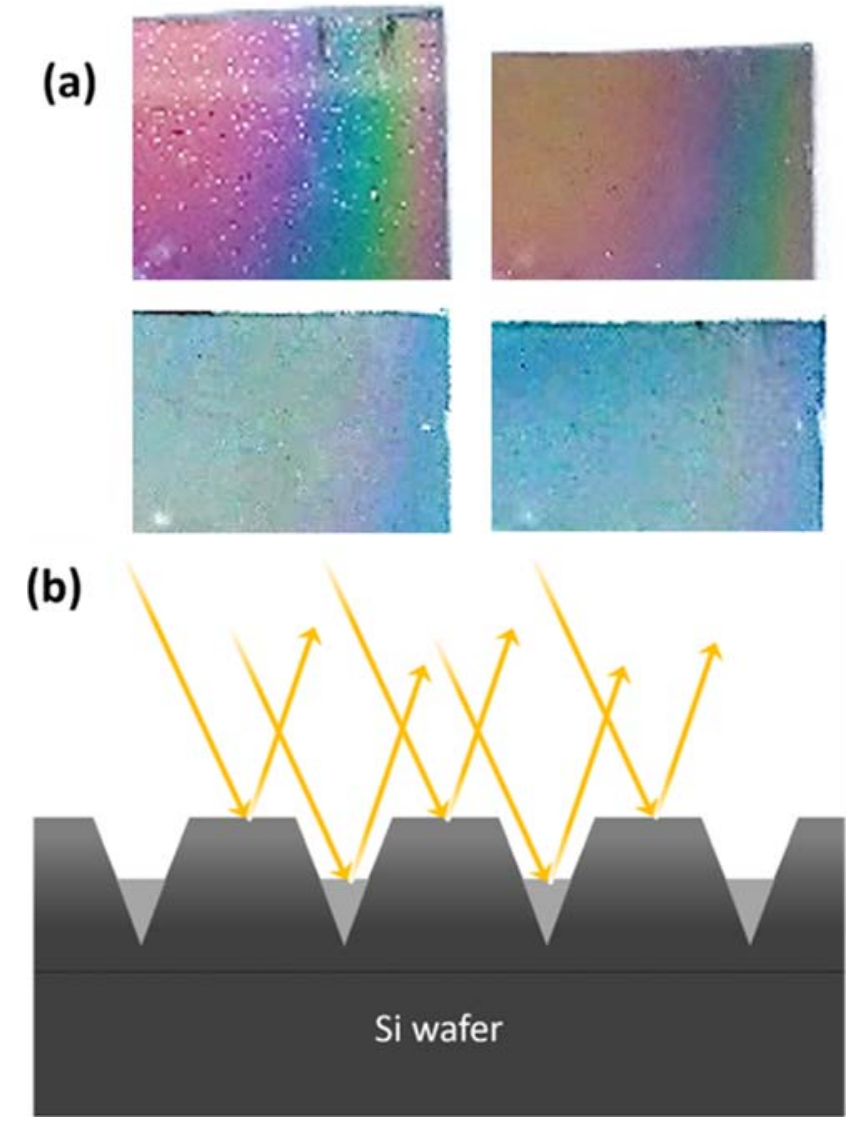

Figure 9: (a) Iridescence (images for four different angles of white light illumination) on plasma etched epitaxial breakdown sample and (b) schematic illustration of the interference effect due to surface texturing.

\section{Conclusions}

By selectively removing amorphous silicon cones formed by epitaxial breakdown during the growth of a c-Si layer, we have demonstrated the formation of randomly placed, micron-scale inverted cones with densities as high as 78 cones $/ 100 \mu \mathrm{m}^{2}$. The selective removal of the amorphous cones occurs due to the much faster etching rate of a-Si:H than c-Si by a low-temperature $\left(175^{\circ} \mathrm{C}\right) \mathrm{H}_{2}$ plasma process. The pre-coating of the reactor walls plays a vital role; in particular, etching is not achieved when the reactor walls are covered in a-Si:H (which is the case immediately after epitaxial growth) due to it being readily etched by the $\mathrm{H}_{2}$ plasma, and leading to chemical transport of silicon onto the sample surface. This can be prevented by pre-coating the reactor walls with a-SiO $\mathrm{x}: \mathrm{H}$ (without the sample present in the reactor), preventing re-deposition, and allowing the selective removal of the amorphous cones. The samples used required no special storage conditions after epitaxy, and were stored in ambient conditions for months before etching, showing that native oxide formation does not prevent one from etching the amorphous cones using this process. Reducing the process temperature from $175^{\circ} \mathrm{C}$ to $120^{\circ} \mathrm{C}$ results in a faster etching of amorphous cones. A non-uniformity of the process is observed due to microloading, as partial etching is observed in the central region while fully etched cones are observed at the edge.

Two interesting optical effects are observed: light trapping/anti-reflectance for fully etched, densely spaced cones, and iridescence for partially etched, sparser cones. A reflectance as low as $2 \%$ has been achieved within the regions of highly dense etched cones (> 65 cones $/ 100 \mu \mathrm{m}^{2}$ ). The optimal cone density for each of these two applications will be different, and approximate equations to calculate 
these optimal densities have been provided. These effects could find applications in photovoltaics or sensing.

\section{Acknowledgements}

The authors would like to thank Jongwook Kim (LPMC, École Polytechnique, France) for his help with reflectance measurements.

\section{References}

[1] D.J. Eaglesham, Semiconductor molecular-beam epitaxy at low temperatures, J. Appl. Phys. 77 (1995) 3597-3617. https://doi.org/10.1063/1.358597.

[2] C.W. Teplin, E. Iwaniczko, B. To, H. Moutinho, P. Stradins, H.M. Branz, Breakdown physics of lowtemperature silicon epitaxy grown from silane radicals, Phys. Rev. B - Condens. Matter Mater. Phys. 74 (2006) 4-8. https://doi.org/10.1103/PhysRevB.74.235428.

[3] J. Platen, B. Selle, I. Sieber, S. Brehme, U. Zeimer, W. Fuhs, Low-temperature epitaxial growth of Si by electron cyclotron resonance chemical vapor deposition, Thin Solid Films. 381 (2001) 22-30. https://doi.org/10.1016/S0040-6090(00)01214-1.

[4] R. Cariou, M. Labrune, P. Roca i Cabarrocas, Thin crystalline silicon solar cells based on epitaxial films grown at $165^{\circ} \mathrm{C}$ by RF-PECVD, Sol. Energy Mater. Sol. Cells. 95 (2011) 2260-2263. https://doi.org/10.1016/j.solmat.2011.03.038.

[5] M. Labrune, X. Bril, G. Patriarche, L. Largeau, O. Mauguin, P. Roca i Cabarrocas, Epitaxial growth of silicon and germanium on (100)-oriented crystalline substrates by RF PECVD at $175^{\circ} \mathrm{C}$, EPJ Photovoltaics. 3 (2012). https://doi.org/10.1051/epjpv/2012010.

[6] M. Labrune, M. Moreno, P. Roca i Cabarrocas, Ultra-shallow junctions formed by quasi-epitaxial growth of boron and phosphorous-doped silicon films at $175^{\circ} \mathrm{C}$ by rf-PECVD, Thin Solid Films. 518 (2010) 2528-2530. https://doi.org/10.1016/j.tsf.2009.09.143.

[7] G. Hamon, N. Vaissiere, R. Cariou, R. Lachaume, J. Alvarez, W. Chen, J.-P. Kleider, J. Decobert, P. Roca i Cabarrocas, Plasma-enhanced chemical vapor deposition epitaxy of Si on GaAs for tunnel junction applications in tandem solar cells, J. Photonics Energy. 7 (2017) 022504. https://doi.org/10.1117/1.jpe.7.022504.

[8] M. Chrostowski, J. Alvarez, A. Le Donne, S. Binetti, P. Roca i Cabarrocas, Annealing of borondoped hydrogenated crystalline silicon grown at low temperature by PECVD, Materials (Basel). 12 (2019) 3795. https://doi.org/10.3390/ma12223795.

[9] R. Léal, F. Haddad, G. Poulain, J.L. Maurice, P. Roca i Cabarrocas, High quality boron-doped epitaxial layers grown at $200^{\circ} \mathrm{C}$ from SiF4/H2/Ar gas mixtures for emitter formation in crystalline silicon solar cells, AIP Adv. 7 (2017) 025006. https://doi.org/10.1063/1.4976685.

[10] J. Thiesen, H.M. Branz, R.S. Crandall, Explanation of the limiting thickness observed in lowtemperature silicon epitaxy, Appl. Phys. Lett. 77 (2000) 3589-3591. https://doi.org/10.1063/1.1328767.

[11] W. Chen, R. Cariou, G. Hamon, R. Leál, J.L. Maurice, P. Roca i Cabarrocas, Influence of deposition rate on the structural properties of plasma-enhanced CVD epitaxial silicon, Sci. Rep. 7 (2017) 1-8. https://doi.org/10.1038/srep43968.

[12] S. Sivasubramaniam, M.M. Alkaisi, Inverted nanopyramid texturing for silicon solar cells using interference lithography, Microelectron. Eng. 119 (2014) 146-150. 
https://doi.org/10.1016/j.mee.2014.04.004.

[13] A. Gaucher, A. Cattoni, C. Dupuis, W. Chen, R. Cariou, M. Foldyna, L. Lalouat, E. Drouard, C. Seassal, P. Roca i Cabarrocas, S. Collin, Ultrathin epitaxial silicon solar cells with inverted nanopyramid arrays for efficient light trapping, Nano Lett. 16 (2016) 5358-5364. https://doi.org/10.1021/acs.nanolett.6b01240.

[14] A. Mavrokefalos, S.E. Han, S. Yerci, M.S. Branham, G. Chen, Efficient light trapping in inverted nanopyramid thin crystalline silicon membranes for solar cell applications, Nano Lett. 12 (2012) 2792-2796. https://doi.org/10.1021/nl2045777.

[15] J. Zhao, A. Wang, M.A. Green, 24.5\% efficiency silicon PERT cells on MCZ substrates and $24.7 \%$ efficiency PERL cells on FZ substrates, Prog. Photovoltaics Res. Appl. 7 (1999) 471-474. https://doi.org/10.1002/(SICI)1099-159X(199911/12)7:6<471::AID-PIP298>3.0.CO;2-7.

[16] M. Moreno, D. Daineka, P. Roca i Cabarrocas, Plasma texturing for silicon solar cells: From pyramids to inverted pyramids-like structures, Sol. Energy Mater. Sol. Cells. 94 (2010) 733-737. https://doi.org/https://doi.org/10.1016/j.solmat.2009.12.015.

[17] D.Z. Dimitrov, C.H. Du, Crystalline silicon solar cells with micro/nano texture, Appl. Surf. Sci. 266 (2013) 1-4. https://doi.org/10.1016/j.apsusc.2012.10.081.

[18] H. Park, S. Kwon, J.S. Lee, H.J. Lim, S. Yoon, D. Kim, Improvement on surface texturing of single crystalline silicon for solar cells by saw-damage etching using an acidic solution, Sol. Energy Mater. Sol. Cells. 93 (2009) 1773-1778. https://doi.org/10.1016/j.solmat.2009.06.012.

[19] P. Roca i Cabarrocas, J.B. Chévrier, J. Huc, A. Lloret, J.Y. Parey, J.P.M. Schmitt, A fully automated hot-wall multiplasma-monochamber reactor for thin film deposition, J. Vac. Sci. Technol. A Vacuum, Surfaces, Film. 9 (1991) 2331-2341. https://doi.org/10.1116/1.577318.

[20] M. Otobe, M. Kimura, S. Oda, Selective Etching of Hydrogenated Amorphous Silicon by Hydrogen Plasma, Jpn. J. Appl. Phys. 33 (1994) 4442-4445. https://doi.org/10.1143/JJAP.33.4442.

[21] S. Veprek, Z. Iqbal, H.R. Oswald, A.P. Webb, Properties of polycrystalline silicon prepared by chemical transport in hydrogen plasma at temperature between 80 and $400^{\circ} \mathrm{C}$, J. Phys. C Solid State Phys. 14 (1981) 295-308. https://doi.org/10.1088/0022-3719/14/3/013.

[22] F. Kail, A. Hadjadj, P. Roca i Cabarrocas, Hydrogen diffusion and induced-crystallization in intrinsic and doped hydrogenated amorphous silicon films, Thin Solid Films. 487 (2005) 126-131. https://doi.org/10.1016/j.tsf.2005.01.049.

[23] R.C. van Oort, M.J. Geerts, J.C. van den Heuvel, J.W. Metselaar, Hydrogen plasma etching of amorphous and microcrystalline silicon, Electron. Lett. 23 (1987) 967-968. https://digitallibrary.theiet.org/content/journals/10.1049/el_19870680 (accessed September 14, 2020).

[24] A. Fontcuberta i Morral, P. Roca i Cabarrocas, Role of hydrogen diffusion on the growth of polymorphous and microcrystalline silicon thin films, Eur. Phys. J. Appl. Phys. 35 (2006) 165-172. https://doi.org/10.1051/epjap.

[25] C. Hedlund, H. -O. Blom, S. Berg, Microloading effect in reactive ion etching, J. Vac. Sci. Technol. A Vacuum, Surfaces, Film. 12 (1994) 1962-1965. https://doi.org/10.1116/1.578990.

[26] V. Depauw, C. Trompoukis, I. Massiot, W. Chen, A. Dmitriev, P. Roca i Cabarrocas, I. Gordon, J. Poortmans, Sunlight-thin nanophotonic monocrystalline silicon solar cells, Nano Futur. 1 (2017) 21001. https://doi.org/10.1088/2399-1984/aa7d7c.

[27] M. Mikikian, M. Cavarroc, L. Couëdel, Y. Tessier, L. Boufendi, Dust particles in low-pressure plasmas: Formation and induced phenomena, Pure Appl. Chem. 82 (2010) 1273-1282. 
